\section{BMJ Open Respiratory Research}

\title{
Last-resort strategies during mask shortages: optimal design features of cloth masks and decontamination of disposable masks during the COVID-19 pandemic
}

\author{
Shovon Bhattacharjee (D) , ${ }^{1,2}$ Prateek Bahl (D) , ${ }^{3}$ Abrar Ahmad Chughtai, ${ }^{4}$ \\ C Raina Maclntyre ${ }^{1,5}$
}

To cite: Bhattacharjee $S$, Bahl P, Chughtai AA, et al. Last-resort strategies during mask shortages: optimal design features of cloth masks and decontamination of disposable masks during the COVID-19 pandemic. BMJ Open Resp Res 2020;7:e000698. doi:10.1136/ bmjresp-2020-000698

- Additional material is published online only. To online (http://dx.doi.org/10. 1136/bmjresp-2020-000698)

Received 29 June 2020 Revised 10 August 2020 Accepted 1 September 2020 view, please visit the journal

\section{ABSTRACT}

Face masks and respirators are the most widely used intervention measures for respiratory protection. In the wake of COVID-19, in response to shortages and lack of availability of surgical masks and respirators, the use of cloth masks has become a research focus. Various fabrics have been promoted with little evidence-based foundation and without guidelines on design principles for optimal performance. In these circumstances, it is essential to understand the properties, key performance factors, filter mechanisms and evidence on cloth masks materials. The general community might also need to decontaminate and reuse disposable, single-use devices as a last resort. We present an overview of the filter materials, filter mechanisms and effectiveness, key performance factors, and hydrophobicity of the common disposable masks, as well as cloth masks. We also reviewed decontamination methods for disposable respiratory devices. As an alternative to surgical masks and respirators, we recommend a cloth mask made of at least three layers (300-350 threads per inch) and adding a nylon stocking layer over the mask for a better fit. Water-resistant fabrics (polyesters/nylon), blends of fabrics and water-absorbing fabrics (cotton) should be in the outside layer, middle layer/layers and inside layer, respectively. The information outlined here will help people to navigate their choices if facing shortages of appropriate respiratory protection during the COVID-19 pandemic.

\section{INTRODUCTION}

The COVID-19 pandemic is expected to (C) Author(s) (or their employer(s)) 2020. Re-use permitted under CC BY-NC. No commercial re-use. See rights and permissions. Published by BMJ.

For numbered affiliations see end of article.

Correspondence to Shovon Bhattacharjee; shovon.bhattacharjee@ student.unsw.edu.au continue for the medium term until an effective vaccine is available. ${ }^{1}$ Respiratory protective gear (RPG) (masks and respirators) are an important non-pharmaceutical intervention for use by health workers, the community and sick patients during the pandemic, which can reduce the risk of infection by $85 \% .^{23}$ In public settings, RPGs work by source control and protecting healthy wearers, whereas for healthcare workers (HCWs) use of RPGs is mainly for personal protection. RPGs not only protect unaffected people from inhaling contaminated droplets and aerosols but also reduce the spread of virus from those who are infected. ${ }^{45} \mathrm{~A}$ medical or surgical mask is designed to protect the wearer from splash or spray and is regulated on the water resistance. It does not fit around the face and the filtration quality is variable. A respirator is designed to filter $>95 \%$ of airborne particles $(<5 \mu \mathrm{m}$ in diameter $)$ and fits around the face to create a seal. Respirators are regulated on their filtration capacity. However, shortages of RPGs is placing HCWs and others at risk globally. ${ }^{6}$ In response to the scarcity of RPGs, there are unprecedented efforts at designing homemade cloth masks globally, using locally available fabrics, some of which involve sewing and others using no-sew methods. ${ }^{78}$ Various mask designs have been promoted with little or no evidence of effectiveness. The US Centers for Disease Control and Prevention (CDC) and WHO have suggested home-made cloth masks, or even bandanas, as the last resort. ${ }^{9} 10$ Potentially, a cloth mask could be designed with features similar to a mask or respirator. ${ }^{70-14}$ Herein, as a last-resort strategy, we outline the principles of good design for a safer cloth mask, based on reported available evidence.

To inform appropriate fabric choices for cloth masks it is important to understand the desirable characteristics and design features of a home-made mask. An understanding of differences between filter mediums used in cloth masks, and the key factors that make masks more effective, can result in safer cloth mask designs. In addition, people may have to decontaminate and reuse disposable RPGs as a last resort. Disposable RPGs cannot be 
reused without compromising filtration efficiency or structural integrity. ${ }^{15}$ Only reusable respirators and cloth masks retain their properties after decontamination or washing. However, the decontamination of disposable products is commonly practised during the COVID-19 pandemic and should be done adequately and safely without compromising filtration efficiency. ${ }^{16}$ It is also essential to understand the evidence around available decontamination methods for single-use RPGs.

We present an overview of the key features of a cloth mask for optimal respiratory protection, optimal design features of cloth masks and the evidence on decontamination methods for single-use RPGs.

\section{METHODS}

We searched MEDLINE Ovid and Scopus databases for relevant articles. The search terms included 'Mask', 'Facemask', 'Respirator', 'Cloth mask', 'surgical mask', 'medical mask', 'N95', 'Mask fabrics', 'Personal protective clothing', 'Filtration', 'Fit', 'Water resistance' and 'Decontamination'. We also searched for unpublished manuscripts in medRxiv and BioRxiv, as well as news and reports using Google. The search was last updated on 3 August 2020. Only articles published in English were considered for the review.

\section{FACTORS FOR OPTIMAL RESPIRATORY PROTECTION}

For any RPG, there are design principles for optimal respiratory protection which deal with the key factors for determining the effectiveness of RPGs in providing adequate protection without compromising the efficiency. The key design factors that determine protection (shown in figure 1) are (1) proper fit and good seal, as air will flow down the path of least resistance-a poor seal will result in the air flowing preferentially through the gaps around the edges of the mask; (2) high filtration efficiency; (3) low breathing resistance; (4) type of filter material; (5) water resistance of the outer layer; (6) high surface area of filter media; (7) number of layers of filter material (at least three); (8) thread count (cloth mask) and fineness of weave; and (9) thickness and pore size of the filter medium. Compromising these principles can reduce effectiveness. Other properties such as antimicrobial activity and retention of filtration and fit after washing or decontamination may add to the protection.

\section{FILTER MATERIALS AND BREATHABILITY}

The selection of appropriate fibrous filter materials ensuring good breathability is very important for filtration performance. Common RPGs depend on both mechanical and electrostatic filter mechanisms. Multilayer filters (different layers with different properties) are commonly used to ensure optimal filtration. ${ }^{17}$ In surgical masks and disposable respirators, three to four layers of non-woven fabrics are commonly used as filter media, with non-woven polypropylene and polyester as the main materials. ${ }^{18}$ The outer layer is water-resistant, whereas the inner layer is hydrophilic to absorb expelled droplets and humidity and provide comfort. The middle layer/layers are usually positively charged, to attract aerosols and particles (which are negatively charged) by electrostatic force. ${ }^{19-21}$ Non-woven fabrics are preferred over woven fabrics because non-wovens provide a large and adjustable surface area that can be customised to various filtration conditions. Non-wovens also have a thicker cross-section, bulk and high permeability, which are further boosted by pleating of the raw materials. ${ }^{22} 23$

During shortages of respirators and surgical masks, the commonly available fabrics used for cloth masks (both natural and synthetic polymer) are cotton, wool, linen,

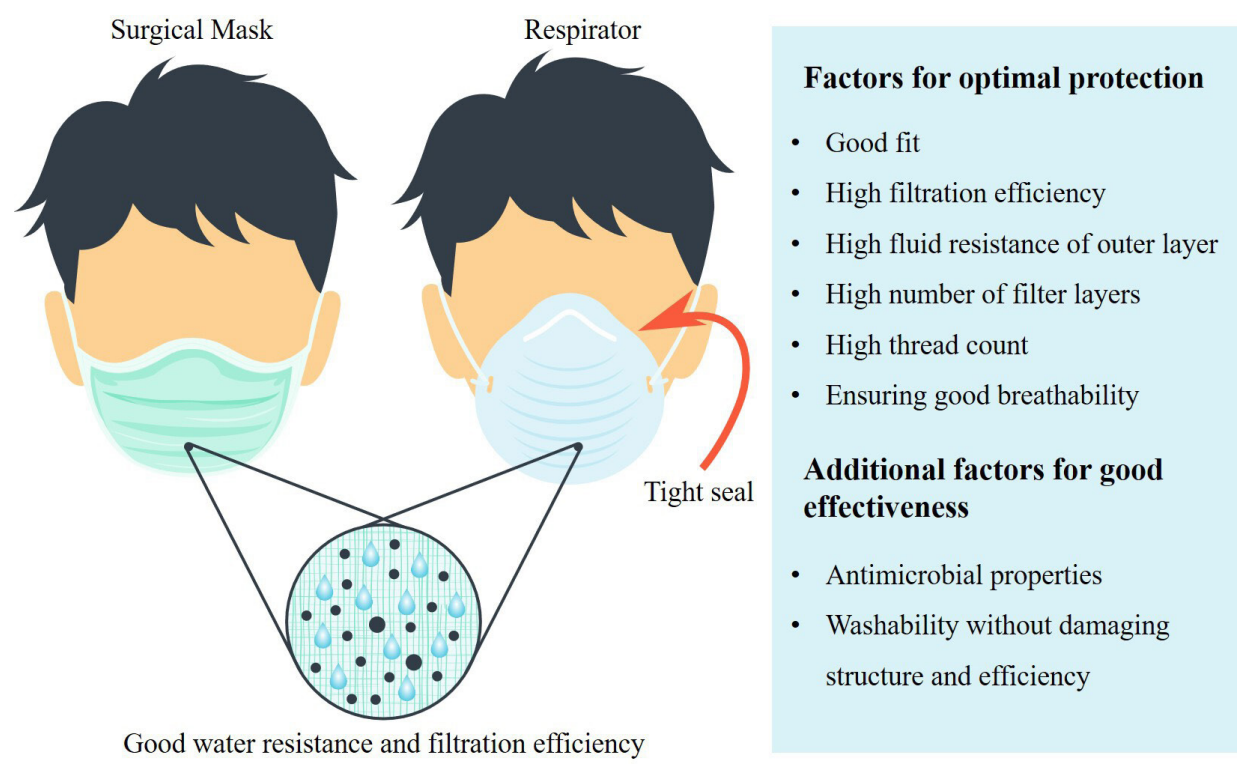

Figure 1 Schematic representation of the factors for an effective respiratory protective gear. 
polyamide, rayon, chiffon, cellulose acetate, polyester, nylon, polyvinyl and blends of these (in various percentages). Acidic polymers (such as polyester), which have acidic groups (-COOH groups or their derivatives) along the backbone, are suitable as filter media because they can efficiently trap and neutralise the virus. When a virus comes in contact with the surface, it gets caught and inactivated by the low $\mathrm{pH}$ of the acidic polymer. ${ }^{23}{ }^{24}$ The CDC recommends using cotton T-shirts, while the WHO suggests a variety of different fabrics including cotton. ${ }^{9} 10$ The cloth mask should consist of multiple layers. Our recent study on cloth masks demonstrated that while a single-layered mask provides some barrier, each layer of cloth masks adds substantial protection from outward respiratory emissions during speaking, coughing and sneezing. ${ }^{25}$ Stretchy fabric like spandex or elastic should be avoided, as when stretched it can reduce the filtration efficiency. Thread count, thickness and pore size of the fabric also play an important role in protection against contaminants. Higher thread count and smaller pore size are beneficial for filtration. However, while selecting materials and number of layers, it is essential to ensure low breathing resistance. ${ }^{26}$ High breathing resistance causes discomfort. Optimisation between filtration efficiency and breathing resistance is very important. The breathing resistance or pressure drop should be within the standard guidelines. The US National Institute for Occupational Safety and Health guidelines indicate that at $85 \mathrm{~L} / \mathrm{min}$ air flow rates surgical mask and respirator filters cannot have an initial breathing resistance $>35 \mathrm{~mm}$ $\mathrm{Hg}$ and exhalation resistance $>25 \mathrm{~mm} \mathrm{Hg} .{ }^{27}$ ASTM (American Society for Testing and Materials) F2100 specifies a 'differential pressure' $<5 \mathrm{~mm} \mathrm{H}_{2} \mathrm{O}$ per square centimetre of material. ${ }^{28}$ The surface area of the filter material also plays an important role in protection. A large surface area contributes to a lower pressure drop for a given inhalation flow rate. ${ }^{29}$ To select the appropriate combination of fabrics for home-made cloth masks, people should be provided simple information about the common filtration mechanisms, water resistance properties and determinants of the filtration performance, which are discussed in the following sections.

\section{FILTRATION MECHANISMS}

There are a variety of contaminant particles in the environment having a variety of sizes ${ }^{30}$ (online supplemental table 1 ). To effectively capture the contaminants in a filter, a combination of physical and electrostatic filtration is necessary. The mechanisms by which RPGs remove contaminant particles and micro-organisms are electrostatic, diffusion, interception and impaction. ${ }^{31-33}$ Electrostatic filtration is predominant for negatively charged small particles (like virus/bacteria), while the other filtration mechanisms work for larger particle sizes. Different filtration mechanisms used by commonly used RPGs are depicted in figure $2 \mathrm{~A}$.

\section{Electrostatic filltration}

This is the most commonly used mechanism by surgical masks and respirators. In electrostatic filtration, the filter media is given a positive charge. When the negatively charged dust particles and the micro-organisms pass through the filter, they are attracted by positively charged filter media and bound on the mask. The electrostatic charge of the filter becomes neutralised over time as the negatively charged particles are captured, hence the filtration efficacy drops rapidly over time. ${ }^{20}$

\section{Diffusion}

In diffusion, the particles contact the fibre due to Brownian (random) motion. When a particle is captured on the fabric, another particle comes to the vacant space to be captured. To enhance the chance of this phenomenon higher microfibre concentration is required. The possibility of capturing particle increases with increasing duration of exposure to particles in the capture zone. ${ }^{31}$

\section{Interception}

In the interception technique, a particle is captured, when the particle following a streamline comes within a distance of one particle radius of the fibre surface. Thus, the particle makes direct contact with the fibre and is captured. In this case, the particles are very small and only the particles following the streamline close to the fibre are captured. ${ }^{31}$

\section{Impaction or inertial impaction}

In the impaction method, owing to inertia, particles leave the streamline flow direction and impact on the fibre. This method mainly occurs for the particle whose size is $>5 \mu \mathrm{m} .{ }^{19} 34$

The schematic of the filtration efficiency of different filtration types is given in figure 2B. The total filtration efficiency is the sum of all the filtration forces, which collectively happen to be weakest in a certain range of particle size which is small enough to escape mechanical filtration and large enough to escape capture due to diffusion. This size of particles is called 'most penetrating particle size' (MPPS), which is found to be different in separate studies. Pelet and Matheux ${ }^{35}$ stated that, when the diameter of the particles is in the range between $0.1 \mu \mathrm{m}$ and $0.5 \mu \mathrm{m}$, the filtration efficiency is the lowest. Balazy et $a l^{36}$ demonstrated that MPPS of charged N95 respirators is around $0.05 \mu \mathrm{m}$, whereas for older uncharged filters MPPS was closer to $0.3 \mu \mathrm{m}$. Overall, particles having diameter range from $0.05 \mu \mathrm{m}$ to $0.5 \mu \mathrm{m}$ can be considered as the MPPS, and this is close to the mean size of most of the viruses. ${ }^{37} 38$ However, viruses generally travel on aerosol particles or droplets of a larger size than the virus itself, which are within the size range to be blocked or filtered by RPGs. 
A.

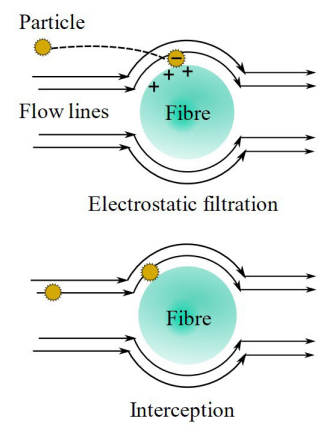

B.

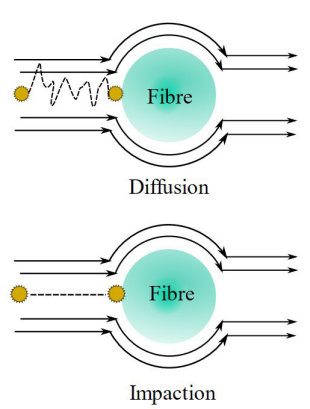

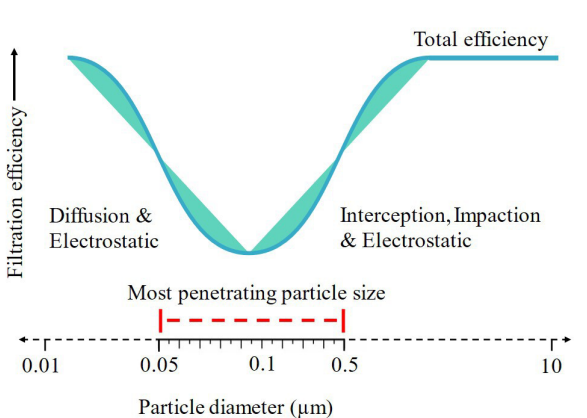

Particle diameter $(\mu \mathrm{m})$

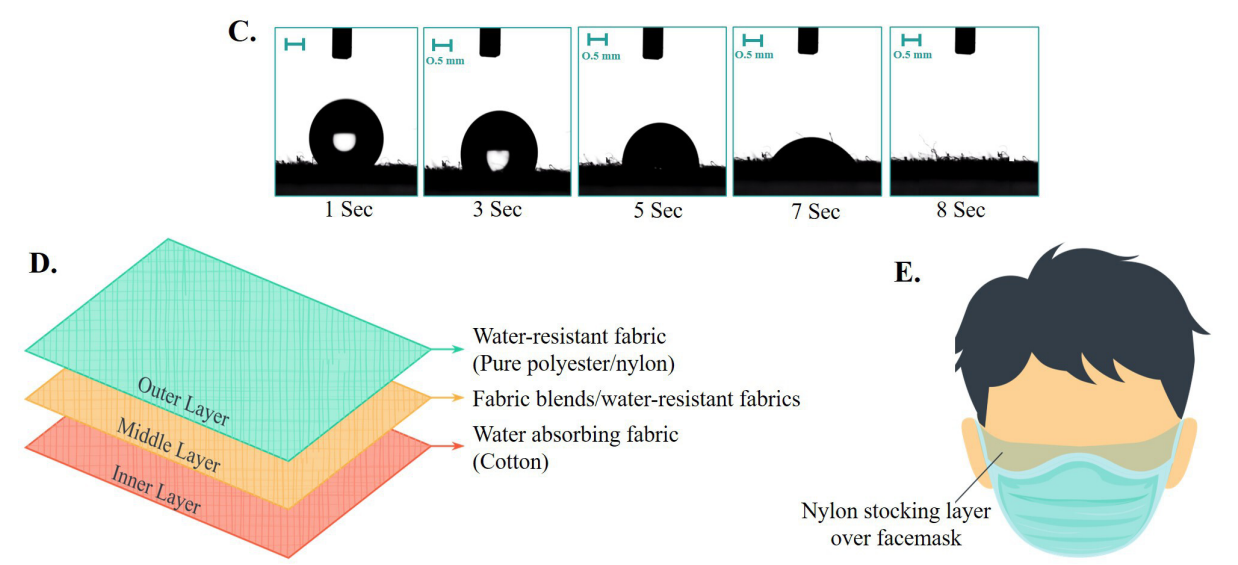

Figure 2 (A) Different filtration mechanisms used by the filter media. The figure depicts how particles are captured in fibres (cross-section) by electrostatic and mechanical forces. (B) Schematic filtration efficiency graph of different filtration types. (C) Real sessile drop images of cotton fabric at the intersection between the drop contour and the fabric surface. Our test revealed that water droplet rapidly absorbs into the fabric within 8s. (D) Schematic of a preferred arrangement of fabrics recommended for cloth mask. (E) Schematic presentation of wearing a nylon stocking over face mask to improve fit.

\section{FIT AND SEAL}

A poor seal across the face is a major concern as nonfiltered air enters into the respiratory system through the leakage. It is important to ensure that the RPG is properly fitted around the wearer's nose, cheeks and chin to provide a tight seal so that air is not inhaled through gaps. In a poorly fitting RPG, the number of particles infiltrating through face seal leakage is much greater than those infiltrating across the filter medium. ${ }^{39}$ Straps, nose bridge, nose piece (nose foam), ear loops and ties of RPGs have an impact on fit. Ear loops generally result in poorer fit than ties. Irrespective of the design, it is important to fit the masks, ensuring proper sealing. ${ }^{40} 41$

The importance of proper fit and seal has been demonstrated in different research. Respirators have better protection than surgical masks and cloth masks. ${ }^{42}$ It has been shown that improper fit and weak seal can decrease respiratory protection by over $60 \%{ }^{7}$ Bad fit and loose sealing also increase the total inward leakage (TIL) of submicron-sized aerosols. Steinle $e t a t^{43}$ tested the impact of facial fit through evaluation of TIL, where they found that a N95 showed the best result (9\% TIL), while other masks (surgical mask and basic flat-fold mask) showed up to $35 \%$ TIL. Oberg and Brosseau ${ }^{44}$ used a different surgical mask to correlate filter performance with the facial fit and concluded that surgical masks do not have sufficient filter performance due to bad facial fit. Fit also plays a substantial impact on respiratory source control. ${ }^{45}$ In comparison with respirators and surgical masks, very few studies have been reported on cloth mask fit.

Davies $e t a t^{47}$ performed fit testing of home-made T-shirt masks in comparison with surgical masks. The Wilcoxon signed-rank test revealed a substantial difference between the fit of a home-made and surgical mask, where a T-shirt mask fit was found to have a much poorer fit than the surgical mask. There has been very little research on improving the fit of surgical masks and cloth masks. However, one recent study showed that applying a nylon stocking over the surgical, cloth and N95 masks improved the filtration, probably by creating a better seal and fit. ${ }^{48}$ Another study showed a combination of rubber bands to make a 'surgical mask brace' and tourniquets can improve the fit. ${ }^{49}$ It is to be noted that when designing a mask, the facial dimensions of the wearer and facial hair are very important. Various research has shown the association of face dimensions and respirator fit. ${ }^{50-59}$ Most studies emphasise the importance of measuring facial dimensions for improving respirator fit. The face anthropometry can vary among races and ethnic groups. ${ }^{59}$ Even face dimension and fit can change as a function of time due to weight loss or gain. ${ }^{55} 58$ Therefore, face anthropometry 
and nose protrusion must be considered for designing fit test panel, head form and finally the respirator. ${ }^{52} 5657$ Both seal check and formal fit testing are important for respiratory protection. ${ }^{56} \mathrm{~A}$ beard usually precludes a good fit and proper seal. ${ }^{60-62}$ As the fit is one of the most important factors for effectiveness, more research needs to be done on improving the fit of respirators and masks.

\section{WATER RESISTANCE}

The fluid-resistant properties of the outer layer of RPGs protect from penetration of fluid droplets containing infectious micro-organisms. The water-resistant outer layer does not absorb fluid droplets and thus protects the inner layer from being contaminated. ${ }^{63}$ Surgical masks and disposable respirators have a well-designed structure (having fluid-resistant outer layer and fluid-absorbing inner layer). Generally, the outer layer of a surgical mask and a disposable respirator is made from spunbonded water-resistant polypropylene, which adds extra protection along with high filtration efficiency. The inner layer is generally treated with hydrophilic plastic/citric acid to make it fluid-absorbing.

Very few studies have reported on the water resistance of different masks ${ }^{64}$ and fabrics for cloth masks. There are some standards for testing the resistance of medical masks to penetration by synthetic blood. ASTM F2100-19e1 provides the performance specifications of materials for medical face masks, which include the resistance to penetration by synthetic blood ${ }^{28}$ whereas ASTM F1862/F1862M-1 $7^{65}$ and ISO 22609:2004 ${ }^{66}$ describe the detailed procedure. Due to the scarcity of surgical masks and respirators ${ }^{67}$ people from many countries have resorted to using a wide range of cloth masks. A home-made mask should imitate the properties of a commercial surgical mask as much as possible. The most common fabrics used are cotton. Cotton fibres are waterabsorbent due to oxygen-bearing hydroxyl groups and capillary action ${ }^{68}$ (figure 2C). It can readily absorb fluid, which is why it is not suitable as a barrier against blood and body fluid exposures. For this reason, cotton cloth masks are less effective against viral infection. ${ }^{69}$ Cotton is more suitable as an inner layer than an outer layer, as the water absorbency improves comfort. Silk and linen fabrics can also quickly absorb water. ${ }^{14} 70$ More suitable water-resistant fabrics include polyester and nylon. Both have very low fluid absorbency and are better choices for an outer layer.

\section{EVIDENCE OF PERFORMANCE OF VARIOUS FABRICS AND CLOTH MASKS FOR RESPIRATORY PROTECTION}

Micro-organisms can spread through contagious droplets and aerosols expelled during various respiratory emissions such as speaking, coughing and sneezing. Online supplemental figure 1 shows a photographic demonstration of a large number of droplets expelled during a sneeze. The extent of horizontal spread of droplets can vary based on different factors, however is greater than the assumed $\sim 1 \mathrm{~m}$ reported for horizontal droplets, which can spread up to $26 \mathrm{~m} .{ }^{71}$ There is inadequate evidence on the filtration performance of available fabrics choices for cloth masks. ${ }^{7}$ Here we summarised the studies that have reported on the performance of cloth mask and other potential fabric choices.

A randomised controlled clinical trial of cloth masks and medical masks in HCWs was performed by MacIntyre et $a l^{69}$ They tested filtration performance according to the respiratory standard AS/NZS1716 and found lower filtration efficiency and higher infection rate in the cloth mask (two layers, made of cotton) in comparison with surgical mask. Our latest study found that increasing layers reduces respiratory emissions from the wearer, with a three-layered medical mask performing better than a two-layered cloth mask, which in turn was better than a single-layered cloth mask. ${ }^{25}$ Konda $e t a l^{7}$ measured the efficiency of common fabrics (cotton, silk, chiffon, flannel, some synthetics and blends of them) used for cloth masks. For single layers, they found a maximum of $80 \%$ and $95 \%$ filtration efficiencies for particle size $<300 \mathrm{~nm}$ and $>300 \mathrm{~nm}$, respectively. They found that because of the combined effect of mechanical and electrostatic filtration, hybrid fabrics (like cotton/silk, cotton/flannel, cotton/chiffon) showed better filtration efficiency for $<300 \mathrm{~nm}$ particles. Higher thread counts also increased efficiency. Davies $e t a t^{77}$ investigated cotton T-shirts as an alternative to surgical masks. They found surgical masks are three times more effective than a home-made cotton mask, and cotton-polyester blend is better than pure cotton. Rengasamy et $a l^{72}$ examined the performance of cloth masks and common fabric materials (sweatshirts, T-shirts, towels, scarves of a mixture of cotton and polyesters). They found marginal respiratory protection by cloth masks, as the penetration of aerosols was much higher than disposable respirators. ${ }^{72}$ Filtration efficiency of cloth masks and surgical masks in comparison with disposable respirators was evaluated by Shakya et $a l,{ }^{73}$ who found that cloth masks are less effective in protecting individuals from $0.25 \mu \mathrm{m}$ particles. ${ }^{73}$ Madsen and Madsen ${ }^{74}$ evaluated the efficiency of different masks and materials. The relative efficiency of the different masks was found in the following order: polypropylene fibres $>$ polyester-rayon fibres $>$ glass fibres $>$ paper. $^{74}$

Historically, circumstantial evidence showed that the cotton gauze mask was effective in military barracks and hospitals during the Manchurian epidemic. ${ }^{75}$ Tea clothbased home-made face masks reduce the risk of respiratory infections. ${ }^{76}$ Case-control studies from the 2003 severe acute respiratory syndrome (SARS) epidemic also suggest cloth masks were beneficial. ${ }^{77} 78$ A recent study showed home-made masks (four-layer kitchen paper + one-layer cloth) blocked $95.15 \%$ of the avian influenza virus in aerosols. ${ }^{79}$ Aydin $e t ~ a l^{14}$ evaluated the performances of different fabrics (from cotton to silk) for cloth masks and reported that the fabrics can substantially block liquid droplets. They found a two-layered cloth mask can block as well as a surgical mask without substantially 


\begin{tabular}{|c|c|c|c|c|}
\hline Categories & Regular cloth mask & Surgical mask & N95 respirator & The ideal cloth mask \\
\hline Physical barrier & $\checkmark$ & $\checkmark \checkmark$ & $\checkmark \checkmark$ & $\checkmark \checkmark$ \\
\hline Water resistance & $x$ & $\checkmark \checkmark$ & $\checkmark \checkmark$ & $\checkmark \checkmark$ \\
\hline Filtration & $x$ & $\checkmark$ & $\checkmark \checkmark$ & $\checkmark \checkmark$ \\
\hline Fit around the face & $x$ & $x$ & $\checkmark$ & $\checkmark$ \\
\hline Breathability & $\checkmark \checkmark$ & $\checkmark \checkmark$ & $\checkmark$ & $\checkmark$ \\
\hline Multiple layers & $x \checkmark$ & $\checkmark \checkmark$ & $\checkmark \checkmark$ & $\checkmark \checkmark$ \\
\hline High thread counts and fine weave & $x \checkmark$ & N/A & N/A & $\checkmark \checkmark$ \\
\hline $\begin{array}{l}\text { Retains properties after multiple } \\
\text { washes with soap/detergents }\end{array}$ & $\checkmark$ & $x$ & $\checkmark x^{\star}$ & $\checkmark \checkmark$ \\
\hline Low cost & $\checkmark$ & $\checkmark x \dagger$ & $x$ & $\checkmark \ddagger$ \\
\hline
\end{tabular}

*Some respirators are disposable and others are reusable.

†Surgical masks are low cost individually, but cannot be reused and so require ongoing supplies, which can be costly.

¥Cost of surgical mask $\sim 10-15$ cents, cloth masks $\sim 20-30$ cents, N95 respirators $\sim \$ 1-3$ and new hybrid mask $~ \$ 3-4$. A hybrid mask will be reusable (up to 1 year) and therefore would be cost-effective in the long run.

N/A, not applicable.

compromising breathability. ${ }^{14}$ Rodriguez-Palacios et al ${ }^{12}$ assessed household textiles (various cotton and polyester) as environmental droplet barriers and found that two-layered textiles can reduce contaminant droplets as effectively as a medical mask/surgical mask. ${ }^{12}$ Chu et $a \hat{l}$ showed that a 12-layered cloth mask was as effective as a surgical mask in protecting against SARS-CoV-2, SARS and the Middle East respiratory syndrome coronavirus (MERS-CoV).

\section{RECOMMENDING CLOTH MASKS AS A BACKUP ALTERNATIVE TO SURGICAL MASK/DISPOSAL RESPIRATORS}

One study showed that wearing a home-made cloth mask is more effective in an influenza pandemic than no mask. ${ }^{11}$ The physical barrier provided by a cloth may be beneficial compared with wearing no mask at all. ${ }^{1100}$ It is important to keep in mind that the balance of filtration and breathability is vital. While selecting materials for better filtration, the breathability should also be considered. The ideal features of a cloth mask are shown in table 1 . Where there is a shortage of commercial RPGs, the community should be provided with guidelines on the optimal cloth mask design which could be recommended as an alternative: multiple layers of fabrics, fine weave, water resistance of the outer layer, improved fit and daily washing. ${ }^{75} 81$ Based on the available evidence discussed, the following recommendations are made for a home-made cloth mask:

\section{Materials}

The cloth mask should consist of multilayer fabrics. The different layers should be of different composition. A variety of fabrics like polyester, nylon, chiffon, silk, cotton, linen and their blends can be used. Blends show better performance than pure fabrics. Stretchy materials such as elastic or spandex should be avoided as their filtration efficiency decreases when stretched. Cotton should only be used as an inner layer.

\section{Layers $\geq 3$}

The inner layer should be made of cotton/linen, as this will absorb expelled droplets and humidity and be more comfortable. The outer layer should be made of polyester/nylon, which will resist aerosol and water droplets. The middle layer/layers can be blends (figure 2D). The thread count should be 300-350 threads per inch.

To improve fit, adding a nylon stocking layered over the mask and tied at the back of the head can provide a better fit ${ }^{48}$ (figure 2E). Alternatively, a mask brace (made of three rubber bands looped together) or two tourniquets fashioned together can be used over the mask to improve the fit. ${ }^{49}$ Daily washing in water that is heated to at least $60^{\circ} \mathrm{C}$ and soap (such as in the laundry) is recommended. The selected fabrics should be able to withstand at least $60^{\circ} \mathrm{C}$.

\section{DECONTAMINATION AND REUSE}

Reuse of single-use RPGs by disinfection goes against manufacturer recommendations and must be done without compromising the efficiency. Shortages of masks and respirators have increased the importance of reviewing decontaminating methods for reuse. Recent research showed that SARS-CoV-2 can survive up to 72 hours on a plastic surface and up to 7 days on a surgical mask. ${ }^{82}{ }^{83}$ Clogging of contaminants on the surface of the mask can also reduce efficiency. ${ }^{84}$ Therefore, any decontaminating method must ensure filtration efficiency is retained. Decontamination of masks and respirators must remove all threat of virus, without sacrificing the filtration efficiency or fit, and be safe (non-toxic) for the user. ${ }^{85}$ However, in the COVID-19 pandemic, HCWs around the world have resorted to decontaminating and reusing 


\begin{tabular}{|c|c|c|c|}
\hline Method/chemicals used & Method reference & Antimicrobial efficiency of methods & Impact of decontamination on fit \\
\hline Ultraviolet irradiation & $85-89$ & $99.9 \%$ & $\begin{array}{l}\text { After three cycles fit test passing } \\
\text { rate is } 90 \%-100 \% \text {. }\end{array}$ \\
\hline Hydrogen peroxide $\left(\mathrm{H}_{2} \mathrm{O}_{2}\right)$ vapour & 8587 & $>99.999 \%$ & Until 20 cycles fit was unaffected. \\
\hline Ethylene oxide & 8690 & Not assessed & Not assessed. \\
\hline Moist heat incubation & $89-91$ & $99.99 \%$ & Passed the fit test. \\
\hline Microwave steam bags & 92 & $99.9 \%$ & Not assessed. \\
\hline Microwave-generated steam & 8791 & $99.9 \%$ & $\begin{array}{l}\text { After } 3 \text { and } 20 \text { times, the fit test } \\
\text { passing rate was } 95 \%-100 \% \text {. }\end{array}$ \\
\hline Hydrogen peroxide $\left(\mathrm{H}_{2} \mathrm{O}_{2}\right)$ liquid & 9093 & Not assessed & Not assessed. \\
\hline Ethanol & 85 & Effective against SARS-CoV-2 & $\begin{array}{l}\text { Substantially distorted mask } \\
\text { integrity. }\end{array}$ \\
\hline $\begin{array}{l}\text { Ozone disinfectant } \\
\text { (SoClean Continuous Positive } \\
\text { Airway Pressure Sanitizer) }\end{array}$ & 95 & Not assessed & $\begin{array}{l}\text { No damage was reported to the } \\
\text { functional property of the mask. }\end{array}$ \\
\hline Rice cooker steam & 96 & Effective against bacteria & Not assessed. \\
\hline
\end{tabular}

masks and respirators. Among the reported available methods (table 2), UVC (Ultraviolet C) irradiation, ${ }^{86-89}$ hydrogen peroxide vapour ${ }^{87}$ and moist heat incubation $^{89-91}$ are the most promising. ${ }^{16}$ For UVC irradiation, the time for effective disinfection may vary in different cases because of the different intensities of radiation in different lamps. Both UVC radiation ${ }^{86-89}$ and hydrogen peroxide vapour ${ }^{85} 87$ provide evidence of killing $\geq 99.9 \%$ bacterial spores and do not significantly impact filtration and fit. The moist heat technique at $65^{\circ} \mathrm{C}$ temperature and $85 \%$ relative humidity (RH) was reported to disinfect $99.99 \%$ virus, ${ }^{91}$ while $60^{\circ} \mathrm{C}$ and $80 \% \mathrm{RH}$ showed minimal effect on fit and filtration. ${ }^{89-91}$ The other methods reported are microwave-generated steam, ${ }^{87} 91$ microwave steam bags, ${ }^{92}$ liquid hydrogen peroxide ${ }^{9093}$ and ethylene oxide. ${ }^{860}$ Both microwave steam and steam bags showed 99.9\% bactericidal capacity, but a negative impact on fit performance. Ethylene oxide is toxic to humans, so should be avoided. ${ }^{94}$ It is to be noted that microwave exposure can cause arcing and sparks to metal nosebands (if any). Liquid hydrogen peroxide has not shown any effect on filtration performance. Ozone disinfectants ${ }^{95}$ and rice cooker steamers ${ }^{96}$ have also been used to disinfect RPGs.

Precautions are required while decontaminating, such as hand hygiene and the use of gloves. UVC radiation is harmful and people should not be exposed to it. ${ }^{86}$ Other methods such as autoclaving, heat drying $\left(160^{\circ} \mathrm{C}\right)$, applying microwave radiation, using isopropyl alcohol $(70 \%)$ and washing with soap and water substantially degraded the filter media, so should be avoided. ${ }^{8693}$ There is some evidence that UVC fails to decontaminate rubber straps. ${ }^{97}$ However, very limited research has been done on decontamination, and the safety of reused personal protective equipment cannot be guaranteed.

\section{CONCLUSIONS}

The severity of the COVID-19 pandemic has resulted in recommendations for cloth mask use by communities in many countries, to ensure that scarce supplies of disposable respirators and surgical masks are available for health workers. While cloth face coverings may not be as protective as surgical masks or respirators, an optimal quality cloth mask can be designed by an understanding of the principles of design and the differences between filter mediums, construction, mechanisms of action of different fabrics, key performance factors and limitations in these common masks. Another approach used during the pandemic to address the shortages of RPGs has been disinfection and reuse of single-use products. For health workers, the evidence supporting the disinfection and reuse of single-use masks is limited, and there is uncertainty around the safety of this practice. HCWs should use respirators, which are $96 \%$ protective compared with $67 \%$ for surgical masks against SARS, MERS-CoV and SARS-CoV-2. ${ }^{3}$ If the choice is between decontaminating a respirator or using a cloth mask, a reused respirator may be preferable to a cloth mask, and hydrogen peroxide vapour may be the best choice. Alternatively, hospitals could invest in reusable elastomeric respirators as a safer option. We believe that the information summarised here will help people to navigate their choices if facing shortages of appropriate respiratory protection during the COVID-19 pandemic. Formal guidance of design principles for cloth masks should be provided by governments where cloth masks are recommended. Mask wearing in the general population with a well-designed cloth mask can flatten the curve in areas of high incidence $^{98}$ and should be used in combination with other non-pharmaceutical options such as social distancing and hand hygiene. 
Author affiliations

${ }^{1}$ Biosecurity Program, Kirby Institute, UNSW Sydney, Kensington, New South Wales, Australia

${ }^{2}$ Department of Applied Chemistry and Chemical Engineering, Noakhali Science and Technology University, Noakhali, Bangladesh

${ }^{3}$ School of Mechanical and Manufacturing Engineering, UNSW Sydney, Kensington, New South Wales, Australia

${ }^{4}$ School of Public Health and Community Medicine, UNSW Sydney,

Kensington, New South Wales, Australia

${ }^{5}$ College of Public Service and Community Solutions and College of Health

Solutions, Arizona State University, Tempe, Arizona, USA

Contributors The manuscript was written through the contributions of all the authors. SB conceptualised and designed the study, analysed the data, and drafted the manuscript. PB analysed the data and revised the manuscript. AAC supervised the study and revised the manuscript. CRM conceptualised the study, supervised the study and revised the manuscript.

Funding This work was supported by a grant from the NHMRC Centre for Research Excellence, Integrated Systems for Epidemic Response (ISER) (grant number 1107393). CRM is supported by an NHMRC Principal Research Fellowship (grant number 1137582). SB is supported by a UNSW Scientia PhD scholarship.

Competing interests None declared.

Patient consent for publication Not required.

Provenance and peer review Not commissioned; externally peer reviewed.

Data availability statement All data relevant to the study are included in the article or uploaded as supplementary information.

Open access This is an open access article distributed in accordance with the Creative Commons Attribution Non Commercial (CC BY-NC 4.0) license, which permits others to distribute, remix, adapt, build upon this work non-commercially, and license their derivative works on different terms, provided the original work is properly cited, appropriate credit is given, any changes made indicated, and the use is non-commercial. See: http://creativecommons.org/licenses/by-nc/4.0/.

ORCID IDs

Shovon Bhattacharjee http://orcid.org/0000-0003-1241-641X

Prateek Bahl http://orcid.org/0000-0002-0978-2286

\section{REFERENCES}

1 Kissler SM, Tedijanto C, Goldstein E, et al. Projecting the transmission dynamics of SARS-CoV-2 through the postpandemic period. Science 2020;368:eabb5793

2 Maclntyre CR, Chughtai AA. Facemasks for the prevention of infection in healthcare and community settings. BMJ 2015;350:h694.

3 Chu DK, Akl EA, Duda S, et al. Physical distancing, face masks, and eye protection to prevent person-to-person transmission of SARS CoV-2 and COVID-19: a systematic review and meta-analysis. The Lancet 2020;395:1973-87.

4 Prather KA, Wang CC, Schooley RT. Reducing transmission of SARS-CoV-2. Science 2020;368:eabc6197:1424

5 Leung NHL, Chu DKW, Shiu EYC, et al. Respiratory virus shedding in exhaled breath and efficacy of face masks. Nat Med 2020;26:676-80

6 Maclntyre CR, Wang Q. Physical distancing, face masks, and eye protection for prevention of COVID-19. The Lancet 2020;395:1950-1.

7 Konda A, Prakash A, Moss GA, et al. Aerosol filtration efficiency of common fabrics used in respiratory cloth masks. ACS Nano 2020.

8 Chandini Raina Maclntyre AC, chi dung THAM, Holly Seale BMJ opinion: BMJ, 2020. Available: https://blogs.bmj.com/bmj/2020/04/ 09/covid-19-should-cloth-masks-be-used-by-healthcare-workersas-a-last-resort/

9 WHO. Advice on the use of masks in the context of COVID-19, 2020. Available: https://www.who.int/publications/i/item/adviceon-the-use-of-masks-in-the community-during-home-care-and-inhealthcare-settings-in-the-context-of-the-novel-coronavirus-(2019ncov)-outbreak [Accessed 9 Jun 2020].

10 CDC. Use of cloth face coverings to help slow the spread of COVID-19, 2020. Available: https://www.cdc.gov/coronavirus/2019 ncov/prevent-getting-sick/diy-cloth-face-coverings.html [Accessed 3 Jun 2020]

11 Davies A, Thompson K-A, Giri K, et al. Testing the efficacy of homemade masks: would they protect in an influenza pandemic? Disaster Med Public Health Prep 2013;7:413-8.
12 Rodriguez-Palacios A, Cominelli F, Basson A, et al. Textile Masks and Surface Covers - A 'Universal Droplet Reduction Model' Against Respiratory Pandemics. medRxiv 2020.

13 Sugrue M, O'Keeffe D, Sugrue R, et al. A cloth mask for underresourced healthcare settings in the COVID19 pandemic. Ir J Med Sci 2020:1-3.

14 Aydin O, Emon MAB, Saif MTA. Performance of fabrics for homemade masks against spread of respiratory infection through droplets: a quantitative mechanistic study. medRxiv 2020.

15 lo M. Reusability of facemasks during an influenza pandemic: facing the flu. Washington, DC: The National Academies Press, 2006.

16 CDC. Decontamination and reuse of filtering Facepiece respirators, 2020. Available: https://www.cdc.gov/coronavirus/2019-ncov/hcp/ ppe-strategy/decontamination-reuse-respirators.html

17 Hutten IM. AThe Handbook of nonwoven filter media. 2nd ed. Elsevier Ltd, 2015

18 Hutten IM. Properties of Nonwoven Filter Media. In: Hutten IM, ed. Handbook of nonwoven filter media. 2nd edn. Oxford: ButterworthHeinemann, 2016: 108-57.

19 Viscusi DJ, Bergman M, Sinkule E, et al. Evaluation of the filtration performance of $21 \mathrm{~N} 95$ filtering face piece respirators after prolonged storage. Am J Infect Control 2009;37:381-6.

20 Lathrache R, Fissan $\mathrm{H}$. Enhancement of particle deposition in filters due to electrostatic effects. Filtration and Separation 1987;24:418-22.

21 Barrett LW, Rousseau AD. Aerosol loading performance of Electret filter media. Am Ind Hyg Assoc J 1998;59:532-9.

22 Zobel S, Gries T. The use of nonwovens as filtration materials. In: Chapman RA, ed. Applications of Nonwovens in technical Textiles. Woodhead Publishing, 2010: 160-83.

23 Bhattacharjee S, Joshi R, Chughtai AA, et al. Graphene modified multifunctional personal protective clothing. Adv Mater Interfaces 2019;6:1900622

24 Kocak G, Tuncer C, Bütün V. pH-Responsive polymers. Polym Chem 2017;8:144-76.

25 Bahl P, Bhattacharjee S, de Silva C, et al. Face coverings and mask to minimise droplet dispersion and aerosolisation: a video case study. Thorax 2020:thoraxjnl-2020-215748.

$26 \mathrm{Kim}$ J-H, Roberge RJ, Powell JB, et al. Pressure drop of filtering facepiece respirators: how low should we go? Int J Occup Med Environ Health 2015;28:71-80.

27 CDC. N95 respirators and surgical masks, 2009. Available: https:// blogs.cdc.gov/niosh-science-blog/2009/10/14/n95/

28 F2100-19e AA. ASTM F2100-19e1, standard specification for performance of materials used in medical face masks. West Conshohocken, PA: ASTM International, 2019.

29 Niezgoda G, Kim J-H, Roberge RJ, et al. Flat fold and cup-shaped N95 filtering facepiece respirator face seal area and pressure determinations: a stereophotogrammetry study. J Occup Environ Hyg 2013;10:419-24.

30 Hutten IM. Introduction to Nonwoven Filter Media. In: Hutten IM, ed. Handbook of nonwoven filter media. 2nd Edn. Oxford: ButterworthHeinemann, 2016: 1-52.

31 Hinds WC. Aerosol technology : properties, behavior, and measurement of airborne particles. 2nd ed. New York (N.Y): Wiley, 1999.

32 Hutten IM. Filtration Mechanisms and Theory. In: Hutten IM, ed. Handbook of nonwoven filter media (second edition. Oxford: Butterworth-Heinemann, 2016: 53-107.

33 Bibliography. Handbook of nonwoven filter media. Second Edition. Oxford: Butterworth-Heinemann, 2016: 619-32.

34 AMJIdAe D. Pathogen inactivation and filtration efficacy of a new anti-microbial and anti-viral surgical facemask and N95 against dentistry-associated microorganisms 2012;7:36-42.

35 Pelet T, Matheux F. O017: a novel antiviral technology for air filtration. Antimicrob Resist Infect Control 2013;2:017.

36 Balazy A, Toivola M, Reponen T, et al. Manikin-based performance evaluation of N95 filtering-facepiece respirators challenged with nanoparticles. Ann Occup Hyg 2006;50:259-69.

37 Metreveli G, Wågberg L, Emmoth E, et al. A size-exclusion Nanocellulose filter paper for virus removal. Adv Healthc Mater 2014:3:1546-50.

38 van Reis R, Zydney A. Membrane separations in biotechnology. Curr Opin Biotechnol 2001;12:208-11.

39 Grinshpun SA, Haruta H, Eninger RM, et al. Performance of an N95 filtering facepiece particulate respirator and a surgical mask during human breathing: two pathways for particle penetration. $J$ Occup Environ Hyg 2009;6:593-603.

40 Lam SC, Lui AKF, Lee LYK, et al. Evaluation of the user seal check on gross leakage detection of 3 different designs of N95 filtering facepiece respirators. Am J Infect Control 2016;44:579-86. 
41 Lawrence RB, Duling MG, Calvert CA, et al. Comparison of performance of three different types of respiratory protection devices. J Occup Environ Hyg 2006;3:465-74.

42 Maclntyre CR, Chughtai AA. A rapid systematic review of the efficacy of face masks and respirators against coronaviruses and other respiratory transmissible viruses for the community, healthcare workers and sick patients. Int J Nurs Stud 2020;108:103629.

43 Steinle S, Sleeuwenhoek A, Mueller W, et al. The effectiveness of respiratory protection worn by communities to protect from volcanic ash inhalation. Part II: total inward leakage tests. Int J Hyg Environ Health 2018;221:977-84.

44 Oberg T, Brosseau LM. Surgical mask filter and fit performance. Am $J$ Infect Control 2008;36:276-82.

45 Mansour MM, Smaldone GC. Respiratory source control versus receiver protection: impact of facemask fit. $J$ Aerosol Med Pulm Drug Deliv 2013;26:131-7.

46 Patel RB, Skaria SD, Mansour MM, et al. Respiratory source control using a surgical mask: An in vitro study. J Occup Environ Hyg 2016;13:569-76.

47 Davies A, Thompson K-A, Giri K, et al. Testing the efficacy of homemade masks: would they protect in an influenza pandemic? Disaster Med Public Health Prep 2013;7:413-8.

48 Mueller AV, Fernandez LA. Assessment of fabric masks as alternatives to standard surgical masks in terms of particle filtration efficiency. medRxiv 2020.

49 Saggese NP, Rose AL, Murtagh K, et al. An interim solution to the decreased availability of respirators against COVID-19. Anesth Analg 2020.

$50 \mathrm{Han} \mathrm{DH}$. Fit factors for quarter masks and facial size categories. Ann Occup Hyg 2000;44:227-34.

51 Han D-H, Choi K-L. Facial dimensions and predictors of fit for halfmask respirators in Koreans. AlHA Journal 2003;64:815-22.

52 Zhuang Z, Coffey CC, Ann RB. The effect of subject characteristics and respirator features on respirator fit. J Occup Environ Hyg 2005;2:641-9.

53 Liu Y, Zhuang Z, Coffey CC, et al. Inward leakage variability between respirator fit test panels - Part II. probabilistic approach. J Occup Environ Hyg 2016;13:604-11.

54 Oestenstad RK, Elliott LJ, Beasley TM. The effect of gender and respirator brand on the association of respirator fit with facial dimensions. J Occup Environ Hyg 2007;4:923-30.

55 Zhuang Z, Bergman M, Brochu E, et al. Temporal changes in filtering-facepiece respirator fit. J Occup Environ Hyg 2016;13:265-74.

56 Manganyi J, Wilson KS, Rees D. Quantitative respirator fit, face sizes, and determinants of fit in South African diagnostic laboratory respirator users. Ann Work Expo Health 2017;61:1154-62.

57 Lin Y-C, Chen C-P. Characterization of small-to-medium headand-face dimensions for developing respirator fit test panels and evaluating fit of filtering facepiece respirators with different faceseal design. PLoS One 2017;12:e0188638.

58 Zhuang Z, Benson S, Lynch S, et al. Laboratory study to assess causative factors affecting temporal changes in filtering Facepiece respirator fit: Part I - pilot study. J Occup Environ Hyg 2011;8:729-39.

59 Yang L, Shen H, Wu G. Racial differences in respirator fit testing: a pilot study of whether American fit panels are representative of Chinese faces. Ann Occup Hyg 2007;51:415-21.

60 Stobbe TJ, daRoza RA, Watkins MA. Facial hair and respirator fit: a review of the literature. Am Ind Hyg Assoc J 1988;49:199-204.

61 Floyd EL, Henry JB, Johnson DL. Influence of facial hair length, coarseness, and areal density on seal leakage of a tight-fitting halfface respirator. J Occup Environ Hyg 2018;15:334-40.

62 Balkhyour MA. Evaluation of full-facepiece respirator fit on fire fighters in the municipality of Jeddah, Saudi Arabia. Int J Environ Res Public Health 2013;10:347-60.

63 Mates JE, Schutzius TM, Bayer IS, et al. Water-Based Superhydrophobic coatings for nonwoven and cellulosic substrates. Ind Eng Chem Res 2014;53:222-7.

64 Rengasamy S, Sbarra D, Nwoko J, et al. Resistance to synthetic blood penetration of National Institute for occupational safety and Health-approved N95 filtering facepiece respirators and surgical N95 respirators. Am J Infect Control 2015;43:1190-6.

65 ASTM. ASTM F1862 / F1862M-17, standard test method for resistance of medical face masks to penetration by synthetic blood (horizontal projection of fixed volume at a known velocity. West Conshohocken, PA: ASTM International, 2017.

66 ISO. Iso 22609:2004, clothing for protection against infectious agents-Medical face masks-Test method for resistance against penetration by synthetic blood (fixed volume, horizontally projected. Geneva, Switzerland: ISO, 2004.
67 Mahase E. Novel coronavirus: Australian GPs raise concerns about shortage of face masks. BMJ 2020;368:m477.

68 Bhattacharjee S, Macintyre CR, Wen X, et al. Nanoparticles incorporated graphene-based durable cotton fabrics. Carbon N Y 2020;166:148-63.

69 Maclntyre CR, Seale H, Dung TC, et al. A cluster randomised trial of cloth masks compared with medical masks in healthcare workers. BMJ Open 2015;5:e006577.

70 Bhattacharjee S, Macintyre CR, Bahl P, et al. Reduced graphene oxide and nanoparticles incorporated durable Electroconductive silk fabrics. Adv Mater Interfaces 2020;17:2000814.

71 Bourouiba L. Turbulent gas clouds and respiratory pathogen emissions: potential implications for reducing transmission of COVID-19. JAMA 2020. doi:10.1001/jama.2020.4756. [Epub ahead of print: 26 Mar 2020].

72 Rengasamy S, Eimer B, Shaffer RE. Simple respiratory protection-evaluation of the filtration performance of cloth masks and common fabric materials against 20-1000 nm size particles. Ann Occup Hyg 2010;54:789-98.

73 Shakya KM, Noyes A, Kallin R, et al. Evaluating the efficacy of cloth facemasks in reducing particulate matter exposure. J Expo Sci Environ Epidemiol 2017;27:352-7.

74 Madsen PO, Madsen RE, REJTAJoS M. A study of disposable surgical masks. Am J Surg 1967;114:431-5.

75 Dato VM, Hostler D, Hahn ME. Simple respiratory mask. Emerg Infect Dis 2006;12:1033-4.

76 van der Sande M, Teunis P, Sabel R. Professional and home-made face masks reduce exposure to respiratory infections among the general population. PLoS One 2008;3:e2618.

77 Wu J, Xu F, Zhou W, et al. Risk factors for SARS among persons without known contact with SARS patients, Beijing, China. Emerg Infect Dis 2004:10:210-6.

78 Lau JTF, Tsui H, Lau M, et al. Sars transmission, risk factors, and prevention in Hong Kong. Emerg Infect Dis 2004;10:587-92.

$79 \mathrm{Ma} \mathrm{Q}-\mathrm{X}$, Shan $\mathrm{H}$, Zhang $\mathrm{H}-\mathrm{L}$, et al. Potential utilities of mask wearing and instant hand hygiene for fighting SARS-CoV-2. J Med Virol 2020. doi:10.1002/jmv.25805. [Epub ahead of print: 31 Mar 2020].

80 Javid B, Weekes MP, Matheson NJ. Covid-19: should the public wear face masks? BMJ 2020;369:m1442.

81 Quesnel LB. The efficiency of surgical masks of varying design and composition. Br J Surg 1975;62:936-40.

82 van Doremalen N, Bushmaker T, Morris DH, et al. Aerosol and surface stability of SARS-CoV-2 as compared with SARS-CoV-1. N Engl J Med Overseas Ed 2020;382:1564-7.

83 Chin AWH, Chu JTS, Perera MRA, et al. Stability of SARS-CoV-2 in different environmental conditions. Lancet Microbe 2020;1:e10.

84 Krzyżanowski J, Majchrzycka K. Clogging of filtering material systems used for disposable respirators. Int J Occup Saf Ergon 1997;3:191-202.

85 Smith JS, Hanseler $\mathrm{H}$, Welle J, et al. Effect of various decontamination procedures on disposable N95 mask integrity and SARS-CoV-2 infectivity. medRxiv 2020.

86 Viscusi DJ, Bergman MS, Eimer BC, et al. Evaluation of five decontamination methods for filtering facepiece respirators. Ann Occup Hyg 2009;53:815-27.

87 Bergman MS, Viscusi DJ, Heimbuch BK, et al. Evaluation of multiple (3-Cycle) decontamination processing for filtering Facepiece respirators. J Eng Fiber Fabr 2010;5:155892501000500405.

88 Lindsley WG, Martin SB, Thewlis RE, et al. Effects of ultraviolet germicidal irradiation (UVGI) on N95 respirator filtration performance and structural integrity. J Occup Environ Hyg 2015;12:509-17.

89 Viscusi DJ, Bergman MS, Novak DA, et al. Impact of three biological decontamination methods on filtering facepiece respirator fit, odor, comfort, and donning ease. J Occup Environ Hyg 2011;8:426-36.

90 Bergman MS, Viscusi DJ, Heimbuch BK, et al. Evaluation of multiple (3-Cycle) decontamination processing for filtering Facepiece respirators. J Eng Fiber Fabr 2010;5:155892501000500-41.

91 Heimbuch BK, Wallace WH, Kinney K, et al. A pandemic influenza preparedness study: use of energetic methods to decontaminate filtering facepiece respirators contaminated with $\mathrm{H} 1 \mathrm{~N} 1$ aerosols and droplets. Am J Infect Control 2011;39:e1-9.

92 Fisher EM, Williams JL, Shaffer RE. Evaluation of microwave steam bags for the decontamination of filtering facepiece respirators. PLoS One 2011;6:e18585.

93 Viscusi DJ, King WP, Shaffer RE. Effect of decontamination on the filtration efficiency of two filtering facepiece respirator models. $J$ Int Soc Respir Prot 2007;24:93-107.

94 Fluxman C. Use of Ethylene Oxide to Sterilize Face Masks "Extremely Hazardous". SunNews, 2020. 
95 Burkhart CG. Ozone disinfectants like SoClean CPAP sanitizer can be used to sterilize cloth and n95 masks in the protection against COVID-19. Open Dermatol J 2020;14:14-15.

96 Li DF, Cadnum JL, Redmond SN, et al. It's not the heat, it's the humidity: effectiveness of a rice cooker-steamer for decontamination of cloth and surgical face masks and N95 respirators. Am J Infect Control 2020;48:854-5.
97 N95DECON. N95DECON and MGB COVID innovation present webinar on science and implementation of N95 decontamination and reuse: N95DECON, 2020. Available: https://www.n95decon.org/ [Accessed 9 Jun 2020].

98 Ngonghala CN, Iboi E, Eikenberry S, et al. Mathematical assessment of the impact of non-pharmaceutical interventions on curtailing the 2019 novel coronavirus. Math Biosci 2020;325:108364. 